\title{
Reply to: Smith et al., "Comment on supposed holothurian body fossils from the middle Ordovician of Wales (Botting and Muir, Palaeontologia Electronica: 15.1.9A)"
}

\author{
Joseph P. Botting and Lucy A. Muir
}

\begin{abstract}
The comment by Smith et al. rejects a previous interpretation of Middle Ordovician fossils as holothurians. This rejection is based on the use of inappropriate techniques to study the fossils, and insufficient consideration of their taphonomy. The fossils can be shown not to be sponges (the suggested alternative interpretation), and despite the taphonomic limitations, do show echinoderm characters such as the pentagonal oral ring and ambulacral structures.
\end{abstract}

Joseph P. Botting. State Key Laboratory of Geology and Palaeontology, Nanjing Institute of Geology and Palaeontology, 39 East Beijing Road, Nanjing 210008, China. acutipuerilis@yahoo.co.uk; Lucy A. Muir. State Key Laboratory of Geology and Palaeontology, Nanjing Institute of Geology and Palaeontology, 39 East Beijing Road, Nanjing 210008, China. lucy@asoldasthehills.org

Keywords: Echinodermata; imaging techniques; problematic fossils

\section{COMMENT}

The comment by Smith et al. constitutes a rebuttal of our description of a new Ordovician holothurian from the Builth Inlier of Wales. They argue that the fossils lack any echinoderm characteristics and cannot be therefore assigned to the holothurians. Criticisms of this type are invariably useful, but in this case we disagree with their conclusions; after detailed consideration of their arguments, and despite the obviously imperfect preservation of the specimens, we remain convinced that the fossils are indeed holothurians. The main problems with Smith et al.'s rebuttal are that their arguments largely ignore the taphonomy of the deposit, that they used inappropriate tech- niques to study the material, and that their alternative interpretation of the fossils is demonstrably incorrect.

\section{TAPHONOMY}

One of the main arguments that Smith et al. raise is that calcareous ring elements always preserve stereom, even in isolated material. However, this is not the case; although it is present in some isolated elements preserved as the original calcite, Early Palaeozoic echinoderm material in general is typically recrystallised, with the stereom lost. It is certainly possible to preserve unrecrystallised material, or high-resolution moulds in fine sediment, but this is unusual in Ordovician siliciclastic 
sediments. Smith et al. mistakenly identify that the coarse reticulate structure seen in our illustration of the mitrate Anatifopsis as typical stereom; instead, this is a much coarser structure specific to that species, and therefore cannot be used to argue that stereom should be preserved in the holothurian. The small cystoid that we illustrated in the same figure shows no sign of stereom, but does include patches of irregular granular material, similar to that seen in Oesolcucumaria. Such preservation of coarse crystalline replacement rather than fine stereom is absolutely typical for this deposit.

Firstly, pyritisation typically destroys the fine structure of a fossil due to coarse crystallites replacing the mineral fabric, and this appears to be always the case in echinoderms (e.g., Glass and Blake, 2004; Glass, 2006). In a recent paper by the same authors (Smith et al., in press) comparing Rhenechinus from the Hunsrück Slate and from Spain, the calcareous Spanish material from marls shows stereom preservation, whereas the pyritised material shows none. Furthermore, the Builth Inlier specimens are weathered. Oxidation of pyrite leads to total recrystallisation, volume increase, and often also migration of material via pore fluids. Therefore, any stereom structure that might have somehow survived the replacement as pyrite would have been destroyed on weathering, and we would not expect to see preservation of normal stereom in any echinoderm specimen from this deposit. The absence of stereom in the specimens under discussion therefore has no bearing on whether they are, or are not, echinoderms.

Secondly, Smith et al. wisely did not clean the iron oxides from the delicate fossil to expose the true surface; unfortunately, this means that for the critical oral ring area they were latexing a randomly-generated internal breakage surface through poorly-consolidated material. In our original study, we used camera lucida (discussed below) to investigate the structure of the oral ring, as a simple unidirectional light source and SEM examination were not sufficient to reveal all the detail available from this type of preservation.

The plates in Oesolcucumaria, as discussed above, are now composed of oxidised pyrite effectively a powdery mass replacing a coarsely crystalline replacement of the original material. It is not reasonable to expect this mode of preservation to yield clear plate morphology and microstructure. It is also not true that all material accepted as holothurian body fossils preserves fine detail of the oral ring. The material illustrated by Smith et al. (figure 3.2) includes an oral ring from a Mazon Creek apo- dan, and shows some areas of irregular preservation, transverse fractures, areas of sulphide replacement, and few clear plate boundaries.

Smith et al.'s criticism that there is no trace of a digestive tract also indicates that they have not considered the preservation in detail, as soft-tissue pyritisation frequently preserves only the surface of the fossil, with three-dimensional preservation of soft tissues requiring more unusual mechanisms such as void-filling (Glass, 2006). To our knowledge, the gut is also not preserved in pyritised Palaeocucumaria from the Hunsrückschiefer, although even labile external tissues such as the tentacles are present (e.g., Stürmer et al., 1980, figure 27).

We acknowledge that the preservation of Oesolcucumaria is indeed non-ideal (primarily due to the extensive weathering), and the fossils must be interpreted in that light. Nonetheless, it was possible for us to obtain a significant amount of information regarding the oral ring and ambulacra with careful application of light microscopy and camera lucida.

\section{TECHNIQUES}

As the holothurians (and other fossils) are preserved as iron oxides, replacing pyrite during weathering, embedded in soft siltstone, both the fossils and matrix are easily damaged. The surfaces of the specimens (especially the holotype) are so delicate that a box was constructed in the field in order to prevent wrapping materials from touching the surface of the fossil and potentially destroying details. Similarly, we did not use liquids for enhancing contrast, as these would likely cause damage to the preserved structures when absorbed by the porous, unconsolidated medium. To investigate the material, and in particular for the details of the ambulacra, we used only low-angle illumination and camera lucida.

Despite acknowledging the delicacy of the specimens, Smith et al. used latex casting on two specimens (including the holotype), a procedure that is prone to causing significant damage to poorly-consolidated, porous material. They state that they used this approach because it is standard for studying echinoderm (including holothurian) material, providing the best way to resolve plate arrangement, and SEM studies are the only way to reveal ossicle microstructure (contradicting their interpretation of structures in our low-resolution light image of Anatifopsis as stereom). This approach was inappropriate for the specimens of Oesolcucumaria. They illustrate only the slightly 


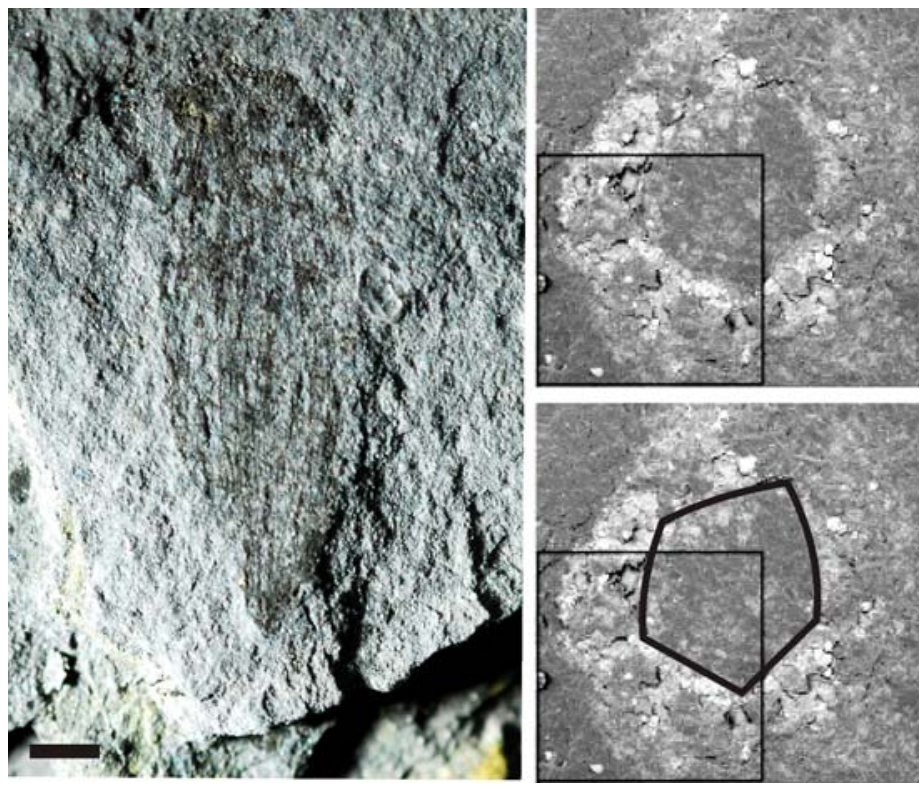

FIGURE 1. Middle Ordovician fossils from the Holothurian Bed, Llandrindod (Botting and Muir 2012). 1, undescribed reticulosan sponge, showing typical preservation of a spicular skeleton in the deposit; specimen will be deposited in the National Museum of Wales after study. 2-3, Oesolcucumaria eostre Botting and Muir, 2012, NHM EE8734 (holotype); detail of oral ring reproduced from Smith et al. (this volume, figure 1.4 inset), with pentagonal inner margin highlighted in 3.

more robust counterpart of the holotype as a latex cast, but even here there is a substantial amount of material adhering to the cast surface. If a cast was also taken of the part, then serious damage may have been done to the preserved structures. We also avoided the use of SEM, as the response of highly porous, effectively uncemented material to being placed in a vacuum is unpredictable, and we felt could have led to damage.

In terms of observational results, SEM is for this type of material less informative than the versatility and subtlety of low-angle light microscopy. Although electron microscopy is clearly critical for the study of extremely fine structures, the preservation of Oesolcucumaria is unlikely to yield such small features (now confirmed by Smith et al.). For this reason, combined with conservation concerns noted above, we instead employed detailed light microscopy. Smith et al. note that the cruciform elements are "difficult to make out under SEM," whereas they are obvious in light microscopy. The reason for this is that the structures are low-relief and require the correct orientation of very lowangle illumination to be clearly revealed; these aspects are difficult or impossible to manipulate in SEM. The oral ring is also difficult to interpret from a single perspective (especially without low-angle light), as the soft oxides replacing the plates have broken irregularly. For this type of material, camera lucida is the most useful approach; although it is open to interpretation, it also makes visible structures that can only be partly recognised from any given perspective.

The choice of technique appears to have been most critical to observation of the ambulacra. Smith et al. state that the presence of the ambulacral zones "simply cannot be confirmed." They do not address the fact that we illustrated this structure not only with camera lucida, but also photographically. We assume that the fact that they could not reproduce the same features using a different technique is due to their technique being inappropriate. It is possible, however, that the structures we observed and illustrated have been damaged or destroyed by Smith et al.'s use of latex.

\section{INTERPRETATION AS SPONGES}

Smith et al's rebuttal implicitly rests on an alternative interpretation of the fossils as sponges. Here we have an advantage over the authors, as we have examined a great many sponge specimens from the same bed, and have extensive experience interpreting sponges from this type of deposit. The fossils can be shown not to be sponges through at least four separate arguments:

1. There are not enough spicules. Sponges in 
this deposit (Figure 1.1) have abundant spicules preserved as iron oxides (large spicules usually with some silica); this is typical of sponges in offshore mudstones, as silica (unlike calcite) was particularly prone to replacement by pyrite, and was more likely to have been preserved than small calcareous elements. The only examples in which spicules are invisible are those in which massive pyritisation of soft tissues obscures details; no specimens have been found preserved as a thin iron oxide film without spicules. Furthermore, the cruciform structures in Oesolcucumaria are visible only in the holotype, and not in any other specimen. This is incompatible with any reticulosan sponge, as the spicules in thin-walled taxa provide structural support for the body wall. Even in the small sponge from Llanfawr Quarries (Botting et al., 2011, cited by Smith et al.) spicules are abundantly visible in SEM, even though they are largely invisible in X-ray or CT images due to absorption by massive pyrite replacing the soft tissue.

2. The oral ring cannot be a thickened oscular margin as seen in the small problematic sponge from the Llanfawr Quarries in Botting et al. (2011). We have seen some hundreds of specimens imaged with X-rays, and on rock surfaces, and those specimens which show a circular outline to the thickened rim are entire sponges that have been preserved upright in the sediment. Where the sponge was compressed obliquely, the more heavily pyritised apical region was also compressed obliquely, as expected - there was no structural division, and no rigidity to the apical section. In Oesolcucumaria the ring is almost always equidimensional (subcircular), despite its occurrence at one end of the ellipsoidal body. This could only happen if the structure was discrete and rigid, and mechanically distinct compared with the rest of the sponge body. This is supported by the presence of isolated rings illustrated in our original description, which Smith et al. do not address. No known sponges, fossil or recent, have a soft wall with a rigidly mineralised oscular margin.

3. If the ring represented an oscular margin, it would not be distinctly angled. Although there are prismatic Palaeozoic sponges, these are universally tetraradial or octaradial, whereas Oesolcucumaria shows pentagonal symmetry.
4. The ambulacral structure has no counterpart in any known sponge.

\section{SKELETAL ELEMENT MORPHOLOGY}

The authors raise the issue that no dermal platelets were found in Oesolcucumaria. This is, however, irrelevant, as no such elements are found in most modern holothurians either. Many holothurians also do not possess anal plates. They also say that "Rod-like and/or cruciform elements do occur in holothurians (figure 2.2-10) but these are never simple acicular"; this is incorrect. Indeed, except for minute spinelets at the ray apices (which would not be preserved in the replaced, weathered material of Oesolcucumaria even if present), some of their own examples are simple acicular structures. Simple cruciform and acicular spicules are also present in other living elasipodidan holothurians (e.g., Hansen, 1975, as cited by Botting and Muir, 2012); in particular, compare with the sclerites of Benthodytes (Hansen, 1975, figure 28.4-5). The fact that Oesolcucumaria apparently possessed spicules that are unusual among modern taxa is hardly surprising given its age, but the form of these spicules does fall within the known variation of living species.

\section{SYMMETRY}

Smith et al. state the Oesolcumaria has no pentaradial symmetry. It would not be a problem if this were so, as their illustrations of other holothurian oral rings (for example) also show no obvious pentaradial symmetry. However, Oesolcucumaria does indeed show pentaradial symmetry, in the inner margin of the oral ring. This is most clearly visible in their figure 1.4 (inset), which we have reclarified in Figure 1.2-3, in which four angles are very clear, and the fifth (upper left) is slightly obscured by dispersed iron oxides.

\section{CONCLUSION}

Overall, we regard Smith et al.'s objections to be unsupported, and their only suggested alternative interpretation to be highly implausible. Oesolcucumaria is not a sponge, and it does possess features diagnostic of echinoderms, and specifically holothurians (discrete oral ring, ambulacra, and pentaradial symmetry). Smith et al.'s rejection of our interpretation rests largely on the fact that they did not find or recognise some of these features, while their arguments are not supported by a plausible alternative interpretation. In our opinion, the reason they did not see these features is that 
they used inappropriate methods that were not sensitive to the nature of the specimens; indeed, we are concerned that they may have damaged the specimens, particularly during the process of latex casting. Although the preservation of the fossils is not ideal, we maintain that careful observation leads to a holothurian interpretation being the only tenable conclusion.

We entirely agree with Smith et al. that betterpreserved material would be enormously useful in interpreting the details of Oesolcucumaria, and hope eventually to collect unweathered specimens. However, although it is very easy to dismiss imperfect material, in our opinion it is important to make whatever objective interpretations are possible from rare fossils. Holothurians have an almost nonexistent Palaeozoic record, with most known examples showing robust structures such as large dermal scales that lead to exquisite and unambiguous fossils (e.g., Jell, 2010). Oesolcucumaria did not possess such structures, and was preserved largely through soft-tissue pyritisation. That it apparently differs in some ways from living holothurians is not at all surprising in the oldest example, and we consider it likely that there was substantial early holothurian diversity that remains unknown. Oesolcucumaria itself cannot provide the answer to holothurian origins; however, it is an example of their Ordovician diversity that in our view is important to take into account in future discussions.

\section{REFERENCES}

Botting, J.P. and Muir, L.A. 2012. Fauna and ecology of the Holothurian Bed, Llandrindod, Wales, UK (Darriwilian, Middle Ordovician), and the oldest articulated holothurian. Palaeontologia Electronica 15.1.9A:28pp.

palaeo-electronica.org/content/2012-issue-1-articles/ 191-welsh-holothurian-bed

Botting, J.P., Muir, L.A., Sutton, M.D., and Barnie, T. 2011. Welsh Gold: a new exceptionally preserved pyritised Ordovician biota. Geology, 39:879-882.

Glass, A. 2006. Pyritised tube feet in a protasterid ophiuroid from the Upper Ordovician of Kentucky, U.S.A. Acta Palaeontologica Polonica, 51:171-184.

Glass, A. and Blake, D.B. 2004. Preservation of tube feet in an ophiuroid (Echinodermata) from the Lower Devonian Hunsrück Slate of Germany and a redescription of Bundenbachia beneckii and Palaeophiomyxa grandis. Paläontologische Zeitschrift, 78:73-95.

Hansen, B. 1975. Systematics and biology of the deepsea holothurians. Pt. 1. Elasipodida. Galathea Report, 13:1-262.

Jell, P.A. 2010. Late Silurian echinoderms from the Yass Basin, New South Wales - the earliest holothurian body fossil and two diploporitan cystoids (Sphaeronitidae and Holocystitidae). Memoirs of the Association of Australasian Palaeontologists, 39:27-41.

Smith, A.B., Reich, M., and Zamora, S. 2013. Comment on supposed holothurian body fossils from the middle Ordovician of Wales (Botting and Muir, Palaeontologia Electronica: 15.1.9A). Palaeontologia Electronica, 16.2A:6pp. palaeo-electronica.org/content/2013/348-ordovicianholothurian

Smith, A.B., Reich, M., and Zamora, S. in press. Morphology and ecological setting of the basal echinoid genus Rhenechinus from the Early Devonian of Spain and Germany. Acta Palaeontologica Polonica.

Stürmer, W., Schaarschmidt, F., and Mittmeyer, H.G. 1980. Versteinertes Leben im Röntgenlicht. Kleine Senckenberg-Reihe, 11:80 pp. 